\title{
Amygdala infusions of an NR2B-selective or an NR2A-preferring NMDA receptor antagonist differentially influence fear conditioning and expression in the fear-potentiated startle test
}

\author{
David L. Walker ${ }^{1,3}$ and Michael Davis ${ }^{1,2}$ \\ ${ }^{1}$ Department of Psychiatry and Behavioral Sciences, School of Medicine, Emory University, Atlanta, Georgia 30329, USA; \\ ${ }^{2}$ The Center for Behavioral Neuroscience, Emory University, Atlanta, Georgia 30329, USA
}

\begin{abstract}
Within the amygdala, most $N$-methyl-D-aspartic acid (NMDA) receptors consist of NR1 subunits in combination with either NR2A or NR2B subunits. Because the particular subunit composition greatly influences the receptors' properties, we investigated the contribution of both subtypes to fear conditioning and expression. To do so, we infused the NR1/NR2B receptor antagonist CP1O1,606 $(0.5,1.5$, or $4.5 \mu \mathrm{g} /$ amygdala) or the NR1/NR2A-preferring antagonist NVP-AAM077 $(0.075,0.25,0.75$, or $2.5 \mu \mathrm{g} / \mathrm{amygdala})$ into the amygdala prior to either fear conditioning (i.e., light-shock pairings) or fear-potentiated startle testing. CP1O1,606 nonmonotonically disrupted fear conditioning but did not disrupt fear expression. NVP-AAMO77 dose-dependently disrupted fear conditioning as well as fear expression. The results suggest that amygdala NR1/NR2B receptors play a special role in fear memory formation, whereas NR1/NR2A receptors participate more generally in synaptic transmission.
\end{abstract}

The $N$-methyl-D-aspartic acid (NMDA) receptor antagonist AP5 prevents fear conditioning when infused into the amygdala prior to light-shock (Miserendino et al. 1990; Walker and Davis 2000), tone-shock (Campeau et al. 1992), or odor-shock (Walker et al. 2005) pairings. In the studies noted above, AP5 did not disrupt fear expression when infused prior to testing. These dissociations suggest a special role for amygdala NMDA receptors in fear memory formation (c.f., Walker and Davis 2002b) but have not been universally observed. Indeed, several groups have found that pretest intra-amygdala AP5 infusions do disrupt fear expression (Maren et al. 1996; Fendt 2001; Lee et al. 2001; Jasnow et al. 2004).

NMDA receptors are heteromeric complexes, requiring the presence of both NR1 and NR2 subunits (c.f., Cull-Candy et al. 2001; Prybylowski and Wenthold 2004). There are several NR2 subtypes, of which two-NR2A and NR2B-occur in the amygdala (e.g., Monyer et al. 1992; Lopez de Armentia and Sah 2003). For several reasons, NR2B subunits have attracted special attention vis-à-vis learning. It has been shown, for example, that they confer to NMDA receptors relatively long-duration excitatory postsynaptic potentials (EPSPs) (e.g., Monyer et al. 1994; Vicini et al. 1998) that may be especially important for associative conditioning (c.f., Tsien 2000). They are also the dominant subtype during development-a time when neural mechanisms of plasticity are especially active (e.g., Laurie et al. 1997; Lopez de Armentia and Sah 2003; for review, see Loftis and Janowsky 2003). Interestingly, binding of the plasticity-associated enzyme calcium/calmodulin-dependent kinase II (CaMKII) to the NR2B subunit renders CaMKII constitutively active (Bayer et al. 2001), and recent results suggest that this interaction is a major determinant of the magnitude of hippocampal long-term potentiation (LTP) (Barria and Malinow 2005). Also, Shin et al. (2006) have reported that whereas the NR2A-preferring antagonist NVP-AAM077 (0.5

\footnotetext{
${ }^{3}$ Corresponding author.
}

E-mail dlwalke@emory.edu; fax (404) 727-3436.

Article is online at http://www.learnmem.org/cgi/doi/10.1101//m.798908. $\mu \mathrm{M})$ produces a much greater inhibition of synaptic transmission in cortico-amygdala and thalamo-amygdala pathways than does the NR2B-selective antagonist ifenprodil $(10 \mu \mathrm{M})(\sim 75 \%$ and $25 \%$ reduction, respectively), only ifenprodil blocks spike-timingdependent LTP in the same pathways. Given then what may be a special role for NR2B-containing receptors in synaptic plasticity, we wondered whether antagonists of these receptors might preferentially disrupt fear conditioning versus fear expression with greater reliability than has previously been found for nonselective NMDA receptor antagonists or for selective antagonists to other NMDA receptor subtypes.

Unfortunately, analyses of the relative contributions of these different NMDA receptor subtypes have been greatly hindered by the lack of subtype-selective antagonists. Importantly, Rodrigues et al. (2001) found that pretraining systemic or intraamygdala ifenprodil infusions disrupted fear conditioning to a tone (see also Blair et al. 2005) and also to a context conditioned stimulus (CS) but had no effect on conditioned freezing when infused prior to testing. More recently, similar effects of ifenprodil were reported for fear extinction learning (Sotres-Bayon et al. 2007). These results are particularly relevant because ifenprodil is highly selective for NR2B- versus NR2A-containing receptors (Williams 1993). However, ifenprodil also acts as an $\alpha 1$ adrenergic (e.g., Chenard et al. 1991) and 5- $\mathrm{HT}_{3}$ (McCool and Lovinger 1995) receptor antagonist, binds to 5- $\mathrm{HT}_{1 \mathrm{~A}}$ (Chenard et al. 1991) and $\delta$ (Karbon et al. 1990; Chenard et al. 1991) receptors, and modestly reduces NMDA-evoked EPSCs even in mice lacking NR2B subunits (Tovar et al. 2000). Genetic manipulation techniques might allow for more selective targeting and, indeed, Tang et al. (1999) have reported that mutant mice overexpressing the NR2B subunit show increased conditioned freezing relative to wild-type controls and improved performance in several other learning tasks as well. More recently, Nakazawa et al. (2006) reported that knock-in mutations that interfere with NR2B phosphorylation also interfere with conditioned freezing (and disrupt amygdala LTP). Although these behavioral effects can be attributed with confidence to influences on NR2B function or number, 
it is unclear whether they reflect primary influences on learning or performance, or increased expression within the amygdala.

The primary goals of this study then were threefold: first, to evaluate the contribution of amygdala NR1/NR2B receptors to fear conditioning and expression using the putatively more selective (i.e., versus ifenprodil) antagonist CP101,606 (Chenard et al. 1995; Chazot et al. 2002; Nagy et al. 2004); second, to assess the generality of the Rodrigues et al. (2001) finding by using a different CS modality (visual) and behavioral measure (fear-potentiated startle); and third, to evaluate for the first time the contribution of amygdala NR2A-containing receptors to fear memory formation and expression using preconditioning and pretest infusions of the NR1/NR2Apreferring antagonist NVP-AAM077 (Feng et al. 2004; Weitlauf et al. 2005; Neyton and Paoletti 2006).

For these studies, rats were chronically implanted with cannulae aimed at the amygdala. After a recovery period of 8-10 d, they received infusions of either CP101,606 or NVP-AAM077 prior to either fear conditioning or fear-potentiated startle testing (i.e., $2 \times 2$ design). Conditioning consisted of either 1 or $2 \mathrm{~d}$ of 10 light-shock pairings each. We typically train animals using 2 consecutive sessions because this produces very reliable conditioning. We included the 1-d conditioning protocol in this study because we were concerned that weak drug effects might go undetected in rats that received the stronger conditioning procedure.

\section{Results}

\section{Cannulae placements}

Placements for rats that met the inclusion criteria (i.e., both cannulae within $0.5 \mathrm{~mm}$ of the basolateral amygdala complex or central amygdala nucleus; $N=298$ ) are shown in Figure 1.

\section{CPIO1,606 effect on fear conditioning}

CP101,606 disrupted fear conditioning when infused into the amygdala prior to each of either 1 or 2 conditioning sessions. ANOVA indicated a significant Dose effect, $F_{(3,125)}=3.98$, $P=0.009$, but not a significant effect of the number of training days, hence the data from animals that received 1 or $2 \mathrm{~d}$ of training are combined for the following analyses. As shown in Figure $2 \mathrm{~A}$, fear-potentiated startle was nonmonotonically related to dose. Importantly, the shape of the nonmonotonic doseresponse curve was replicable in that nearly identical curves were obtained for rats infused with CP101,606 prior to either 1 or $2 \mathrm{~d}$ of conditioning (see Table 1). Post-hoc Dunnett's $t$ comparisons indicated significant differences between the control and the 1.5 $\mu \mathrm{g} /$ amygdala groups $(P=0.002)$ but not between the control and the 0.5 or $4.5 \mu \mathrm{g} / \mathrm{amygdala}$ groups. Moreover, the dose-response curve was significantly fit to a quadratic trend, $t_{(124)}=2.39$. There were no effects on baseline startle (i.e., on noise alone test trials) as assessed with a parallel ANOVA (data not shown).
A similar ANOVA on shock reactivity (see Fig. 3) indicated a significant Dose effect, $F_{(3,125)}=5.93, P=0.001$, as well as a significant Dose $\times$ Training (i.e., 1 versus $2 \mathrm{~d}$ of training) interaction, $F_{(3,125)}=4.82, P=0.003$. To isolate this effect, separate ANOVAs were conducted on the data from rats that received 1 and 2 conditioning sessions. There was not a significant Dose effect in rats that received a single conditioning session. There was, however, a significant Dose effect in rats that received 2 conditioning sessions, $F_{(3,52)}=8.20, P<0.001$. Post-hoc Dunnett's $t$ analysis indicated that footshock reactions in the control group were significantly different from those in the $4.5 \mu \mathrm{g} /$ amygdala group $(P=0.001)$ but were not significantly different from those in the $1.5 \mu \mathrm{g} /$ amygdala group $(P=0.71)$. Thus, the lower footshock reactions occurred in a group of rats that showed normal fear-potentiated startle and the lower fear-potentiated startle scores occurred in a group of rats that showed normal footshock reactions. Moreover, fear-potentiated startle was not correlated with footshock reactivity (i.e., in rats that received vehicle or CP101,606 infusions prior to each of 2 conditioning sessions) as assessed with either Pearson's (i.e., parametric; $P=0.52$ ) or Spearman's (i.e., nonparametric; $P=0.36$ ) correlation analyses. Thus, the relatively modest differences in footshock reactivity were unrelated to and could not account for the effect of CP101,606 on fear conditioning.

\section{CP101,606 effect on fear expression}

CP101,606 administered prior to testing did not significantly influence fear-potentiated startle (Fig. 2B). Statistically, there was neither a significant Dose effect nor a significant effect of the 
A) Pre-Training CP101,606

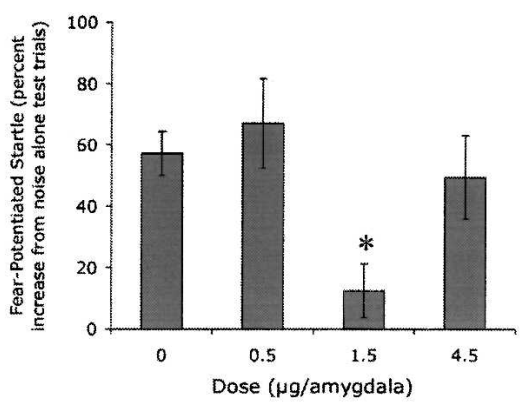

C) Pre-Training NVP-AAM077

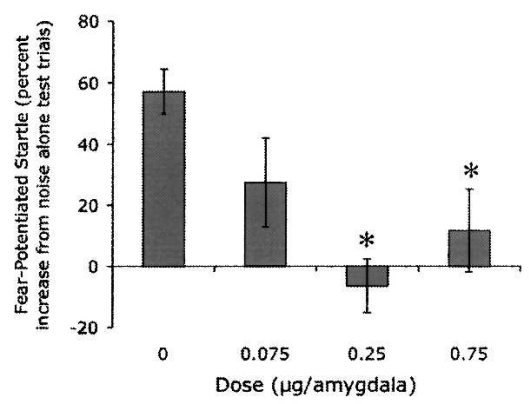

B) Pre-Test CP101,606

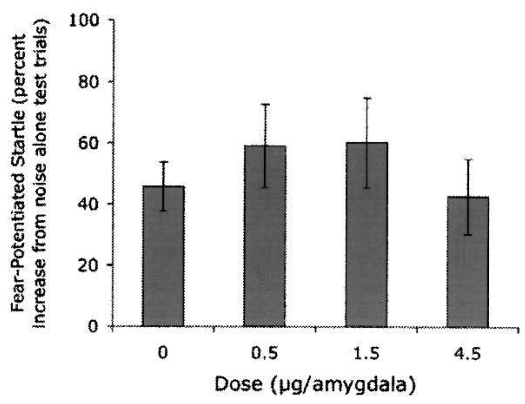

D) Pre-Test NVP-AAM077

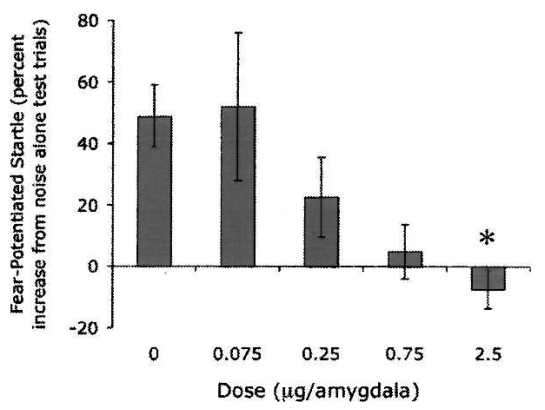

Figure 2. (A) Pretraining CP101,606 infusions disrupted fear conditioning according to a U-shaped dose-response function. ANOVA indicated a significant effect of Dose $(P=0.009)$. (B) Pretest CP101,606 infusions did not significantly influence fear-potentiated startle. (C) Pretraining NVPAAM077 infusions disrupted fear conditioning. ANOVA indicated a significant effect of Dose $(P<0.001)$. (D) Pretest intra-amygdala NVP-AAM077 infusions disrupted fear-potentiated startle. ANOVA indicated a significant effect of Dose $(P=0.046)$. $\left(^{*}\right) P<0.05$ vs $0 \mu \mathrm{g} /$ amygdala (post-hoc Dunnett's $t$ analysis) for all panels.

number of Training Days. Baseline startle amplitude was similarly unaffected (data not shown).

\section{NVP-AAM077 effect on fear conditioning}

NVP-AAM077 disrupted fear conditioning when infused into the amygdala prior to each of either 1 or 2 conditioning sessions (Fig. 2C). ANOVA indicated a significant effect of Dose, $F_{(3,97)}=10.07$, $P<0.001$, but not of the number of Training days. Hence, the data for animals that received 1 or 2 conditioning sessions were combined for the following analyses. Post-hoc Dunnett's $t$ comparisons indicated significant differences between the control group and the groups that received $0.25(P<0.001)$ and 0.75 $(P=0.002) \mu \mathrm{g} /$ amygdala, and a nearly significant difference versus rats that received $0.075(P=0.058) \mu \mathrm{g} /$ amygdala. As with the CP101,606 data, the dose-response curve was nominally U-

Table 1. U-shaped dose-response function for percent potentiation scores in rats infused with CP101,606 prior to either 1 or $\mathbf{2} \mathrm{d}$ of fear conditioning

\begin{tabular}{lcc}
\hline $\begin{array}{l}\text { CP101,606 } \\
\text { Pretraining dose } \\
\text { ( } \boldsymbol{\mu g} \text { /amygdala) }\end{array}$ & $\begin{array}{c}\text { 1 Conditioning } \\
\text { day }\end{array}$ & $\begin{array}{c}\text { 2 Conditioning } \\
\text { days }\end{array}$ \\
\hline 0 (Vehicle) & $47.7 \pm 11.2$ & $65.8 \pm 8.6$ \\
0.5 & $72.8 \pm 21.5$ & $55.6 \pm 17.3$ \\
1.5 & $* 6.29 \pm 12.4$ & $* 17.8 \pm 12.8$ \\
4.5 & $52.7 \pm 22.4$ & $45.8 \pm 15.8$ \\
\hline
\end{tabular}

$* P<0.05$ vs. vehicle. shaped, although this was less pronounced than for the CP101,606infused rats. There were no significant effects on baseline startle amplitude or on footshock reactivity as assessed with parallel ANOVAs (data not shown).

\section{NVP-AAM077 effect on fear expression}

In marked contrast to the NR2B antagonist CP101,606, the NR2A-prefering antagonist NVP-AAM077 significantly disrupted fear-potentiated startle when infused prior to testing $F_{(4,42)}=2.66$, $P=0.046$ (Fig. 2D). The dose-response function was monotonic, $t_{(42)}=3.10$, $P=0.003$ (linear contrast). Dunnett's $t$ comparisons indicated that fear-potentiated startle in the control group was significantly different from that of the $2.5 \mu \mathrm{g} /$ amygdala, $P=0.049$. A parallel ANOVA found no effect of NVPAAM077 on baseline startle amplitude (data not shown) nor did we observe any gross impairments of motor function. Because NVP-AAM077 clearly disrupted expression of fear-potentiated startle in rats given $2 \mathrm{~d}$ of training, we did not also examine its effect in rats trained with the weaker conditioning procedure.

\section{Discussion}

The primary findings are that intraamygdala infusions of the NR1/NR2B receptor antagonist CP101,606 disrupted fear conditioning but not fear expression, whereas intra-amygdala infusions of the NR1/NR2A-preferring antagonist NVP-AAM077 disrupted both. The disruptive effect of pretraining CP101606 infusions, as assessed with fear-potentiated startle, is similar to that of pretraining ifenprodil infusions as assessed with freezing (Rodrigues et al. 2001; Blair et al. 2005). Importantly, neither disrupted fear expression when infused prior to testing. Together with our observation that pretest NVP-AAM077 infusions did disrupt fearpotentiated startle, the results suggest that previously observed disruptions by pretest AP5 (Lee et al. 1988, 2001; Maren et al. 1996; Fendt 2001; Jasnow et al. 2004; Lindquist and Brown 2004) - a broad spectrum NMDA receptor antagonist (e.g., Buller et al. 1994) - are more likely to have resulted from NR1/NR2A rather than NR1/NR2B blockade. This view is compatible with recent behavioral observations that social defeat-induced anxiety in Syrian hamsters is prevented by predefeat intra-amygdala infusions of AP5 or ifenprodil but that only AP5 disrupts defeatinduced induced anxiety when infused prior to testing (Jasnow et al. 2004; D.E. Day, M.A. Cooper, and K.L. Huhman, unpubl.), and with recent electrophysiological findings that the induction of thalamo-amygdala LTP is also disrupted by AP5 and ifenprodil but that only AP5 disrupts synaptic transmission (Chapman and Bellavance 1992; Maren and Fanselow 1995; Bauer et al. 2002). Most importantly, these results strongly suggest that amygdala NR2B-containing NMDA receptors participate directly in fear learning, rather than indirectly via an involvement in synaptic transmission. If the latter were the case, then CP101,606 would also be expected to disrupt fear-potentiated startle when infused prior to testing, as shown previously for other compounds, such 


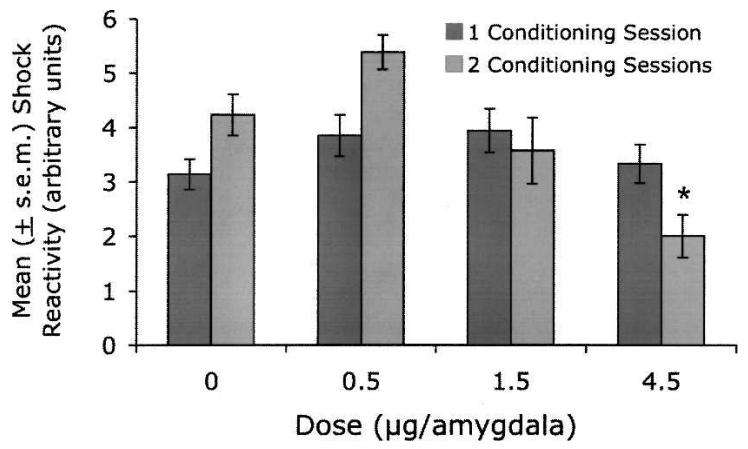

Figure 3. Shock reactivity in rats infused with $\mathrm{CP} 101,606$ prior to training. The mean shock reactivity of rats that received $4.5 \mu \mathrm{g} / \mathrm{amyg}$ dala of CP101,606 prior to each two days of training (averaged response across days) was modestly but significantly lower than that of rats that received pretraining vehicle infusions. As noted previously however, these rats showed normal levels of fear potentiation. Shock reactivity in rats infused with $1.5 \mu \mathrm{g} / \mathrm{amygdala}$, a dose that did disrupt fear conditioning, was normal. As such, effects on footshock perception cannot account for the conditioning deficits produced by pretraining intra-amygdala infusions of CP101,606.

as the AMPA receptor antagonists NBQX or CNQX, which do reduce excitatory neurotransmission (c.f., Walker and Davis 2002b).

Recent findings from Matus-Amat et al. (2007) suggest that nonspecific effects, unrelated to NMDA receptors, might also contribute to the effects on fear expression of intra-amygdala AP5 infusions. They found that D,L-AP5 (the most commonly used form of AP5) and L-AP5 both disrupted conditioned freezing when infused prior to testing but that D-AP5, at equimolar concentrations shown in the same study to disrupt fear conditioning, did not. Because the $D$ but not the $L$ isomer is an NMDA receptor antagonist, these results again suggest a special role for amygdala NMDA receptors in fear learning rather than expression.

Given that pretest NVP-AAM077 infusions did disrupt fearpotentiated startle and that AP5 disrupts NR2A- and NR2Bsubunit-containing receptors with nearly equal efficacy (Beaton et al. 1992; Priestley et al. 1995), it is unclear why disruptive effects of pretest AP5 have not been consistently observed. One possibility is that the disruptive effect of NR1/NR2A blockade is opposed by facilitatory effects of NR1/NR2B blockade. Indeed, we found in this study that fear-potentiated startle was markedly elevated in several groups that received pretest CP101,606 infusions (see Fig. 2B). Nonetheless, disruptive effects of intraamygdala AP5 infusions have been observed in other studies, not only in other laboratories but also, more recently, in our own. For us, this change in the effect of AP5 infusions seems to have coincided with our move from Yale University to Emory University and was accompanied by several other, mostly inconsequential, changes in the behavioral responses of our animals as well. For example, the unconditioned effect of a brief light pulse, which had previously been slightly inhibitory, has now become slightly facilitatory $(<20 \%$ in either direction), whereas the unconditioned increase in startle produced by a longer duration light has decreased in magnitude.

One source of interlaboratory variability may be variability in the composition of NMDA receptors themselves. Many studies have now shown that the ratio of NR2A to NR2B protein or message is dynamic - changing in response to LTP induction (Thomas et al. 1996; Williams et al. 1998), stress (Bartanusz et al. 1995), synaptic activity (Ehlers 2003), NMDA receptor blockade (Bartanusz et al. 1995; Fujisawa and Aoki 2003), development (Laurie et al. 1997; Lopez de Armentia and Sah 2003), and several other manipulations ( $\mathrm{Lu}$ et al. 2005; Wu et al. 2005). Thus, differences in the relative proportions of NR2A to NR2B subunits in rats from different laboratories or suppliers or both may contribute to the variable effects on fear expression of nonselective NMDA receptor antagonists, and perhaps also to variable assessments of the contribution of NMDA receptors to synaptic transmission in amygdala pathways (Li et al. 1996; Mahanty and Sah 1999; Weisskopf and LeDoux 1999; Szinyei et al. 2003).

A surprising aspect of our results was the nonmonotonic dose-response curve observed with pretraining CP101,606 infusions (and to a lesser degree with NVP-AAM077). We are unaware of any precedent for this, although LaLumiere et al. (2004) did report that intra-amygdala AP5 infusions at a single dose either impaired or enhanced inhibitory avoidance retention depending on footshock intensity (see also Kojima et al. 2005 who found that systemic injections of ifenprodil reversed freezing deficits observed in Fyn-transgenic mice which show increased NR2B subunit phosphorylation). Although U- and inverted U-shaped dose-response curves are not uncommon in learning and memory research, their underlying cause remains largely uncertain. With respect to our data, there are several possible, albeit purely conjectural, possibilities. It may be relevant, for example, that NR2B receptor antagonists increase the affinity of glutamate agonists for NMDA receptors, even while simultaneously interfering with channel function (Mott et al. 1998) and that, at low agonist concentrations, the summed effect on NMDA-evoked currents is facilitatory (Kew et al. 1996; Zhang et al. 2000). Insofar as stimulation of presynaptic NMDA receptors, including NR1/ NR2B receptors, increases glutamate release (Woodhall et al. 2001), it is possible that the ascending arm of the nonmonotonic curve reflects increased glutamate binding to presynaptic NR2Bcontaining receptors (assuming that these receptors normally see low concentrations of glutamate), which increases the release of glutamate, which would then be free to bind to postsynaptic NR2A-containing receptors and possibly compensate for the behavioral effect of blocking postsynaptic NR2B-containing receptors.

More generally, the overall effect on behavior of any pharmacological manipulation may reflect the summation of multiple effects on neural function-some of which may be opposite in sign and which may occur at different thresholds. For example, amygdala NR1/NR2B receptors mediate transmission not only onto excitatory projection neurons but also onto inhibitory interneurons (Danober et al. 2000; Sah and Lopez De Armentia 2003; Szinyei et al. 2003). Amygdala NMDA receptors of indeterminate subtype are located not only postsynaptically but also presynaptically (Farb et al. 1995), where they are required for the induction of certain types of LTP (Humeau et al. 2003; Samson and Pare 2005) and may regulate neurotransmitter release as well. In other brain areas, and perhaps the amygdala also, NR2Bcontaining receptors participate not only in LTP but also in longterm depression (e.g., Liu et al. 2004; Massey et al. 2004; Fox et al. 2006; Bartlett et al. 2007). It is possible therefore that the disruptive effects of an intermediate dose of CP101,606 are attenuated or overcome at higher doses by facilitatory effects that occur via different mechanisms.

As previously indicated, we also examined the effect on fear conditioning of the NR1/NR2A-preferring antagonist NVPAAM077. As with CP101,606, pretraining NVP-AAM077 infusions also disrupted conditioning. However, the finding that pretest NVP-AAM077 infusions disrupted fear expression as well suggests that NVP-AAM077 might influence fear conditioning simply by disrupting synaptic transmission. Interestingly, however, fear conditioning appeared to be somewhat more sensitive to NVP-AAM077 than fear expression. For instance, comparable effects (i.e., a reduction of fear-potentiated startle of $\sim 50 \%$ rela- 
tive to vehicle) occurred at $0.075 \mu \mathrm{g}$ /amygdala for acquisition and $0.25 \mu \mathrm{g} /$ amygdala for expression. This suggests that NVPAAM077 effects on fear conditioning are mediated by a disruption of processes that are either different from and more sensitive to NR2A-subunit-containing receptor blockade than those that mediate the effects of NVP-AAM077 on fear expression, or that the effects on fear conditioning are mediated by a disruption of processes that are in addition to those that mediate the effects on fear expression. A specific possibility is that NVP-AAM077 interferes with fear expression by disrupting neural transmission, and disrupts fear learning by this same action in combination with additional effects on receptor-activated biochemical cascades, which are thought to be required for learning-related synaptic plasticity.

Because NVP-AAM077 is only modestly selective for NR2Acontaining receptors (i.e., $\sim 12$-fold difference), it is also possible that the disruptive effect of pretraining infusions was contaminated, at least in part, by actions at NR2B-containing receptors. Indeed, inhibition of both subtypes would nicely account for the muted (relative to CP101,606) U-shaped dose-response curve obtained with this drug (assuming that the nonmonotonic effects of NR1/NR2B blockade were diluted by more linear doseresponse effects of NR1/NR2A blockade), and perhaps also for the greater sensitivity of acquisition versus expression to NVPAAM077 (assuming that NVP-AAM077 effects on acquisition reflect actions on NR2A- plus NR2B-containing receptors, whereas effects on expression reflect, for reasons noted below, effects on NR2A-containing receptors only). For pretest infusions, however, the disruptive effect of NVP-AM077 was almost certainly not attributable, either in part or in whole, to actions at NR2B-subunitcontaining receptors insofar as pretest CP101,606 infusions did not at all disrupt, but nominally improved, fear-potentiated startle. Thus, it seems likely that NR2A-containing receptors in the amygdala can contribute, at least under some circumstances, to fear expression.

In summary, these results provide further support for the view that NR1/NR2B receptors participate in processes that are especially important for fear learning while making minimal contributions to fear expression, the first direct evidence for a dissociation between the involvement of amygdala NR2A- versus NR2B-subunit-containing receptors in fear expression, and surprising evidence for a nonmonotonic relationship between NMDA receptor-subtype blockade and fear conditioning.

\section{Materials and Methods}

\section{Animals}

Male Sprague-Dawley rats (Charles River, Raleigh, NC), weighing between 275 and $350 \mathrm{~g}$ at the time of surgery and housed in groups of 4 in $45 \times 20 \times 24-\mathrm{cm}$ (depth $\times$ width $\times$ height) polycarbonate cages, were maintained on a 12-h light/dark cycle (lights on at $0800 \mathrm{~h}$ ) with food and water available ad libitum. All procedures were conducted under conditions consistent with U.S. Department of Agriculture, Emory University, and National Institutes of Health rules for the care and use of laboratory animals.

\section{Apparatus}

Rats were trained and tested in four identical $8 \times 15 \times 15-\mathrm{cm}$ Plexiglas and wire mesh cages, each suspended between compression springs within a steel frame located within a customdesigned sound-attenuating chamber. The floor of each cage consisted of four $6.0-\mathrm{mm}$ diameter stainless steel bars spaced $18 \mathrm{~mm}$ apart.

Startle responses were evoked by $50-\mathrm{msec} 95-\mathrm{dB}$ white-noise bursts (5-msec rise-decay time, $0-22 \mathrm{kHz}$ ) generated by a Macintosh G3 computer sound file, amplified by a Radio Shack ampli- fier (Model MPA-200; Tandy), and delivered through Radio Shack Supertweeter speakers located $4 \mathrm{~cm}$ in front of each cage. Background noise (60-dB wideband) was produced by an ACO Pacific white-noise generator (Model 3024) and was delivered through the same speakers as those used to provide background noise. Sound level measurements were made with a Brüel \& Kjaer model 2235 sound-level meter (A scale; random input) with the microphone (Type 4176) located $10 \mathrm{~cm}$ from the center of the speaker, which approximates the distance of the rat's ear from the speaker during testing.

Startle response amplitudes were quantified using an accelerometer (model U321AO2; PCB Piezotronics) affixed to the bottom of each cage. Thus, cage movement (e.g., produced by the rats' startle response) resulted in displacement of the accelerometer, which in turn produced a voltage output proportional to the velocity of cage movement. This output was amplified (PCB Piezotronics, Model 483B21) and digitized on a scale of 0-9.98 units by an InstruNET device (Model 100B; GW Instruments) interfaced to a Macintosh G3 computer. Startle amplitude was defined as the maximal peak-to-peak voltage that occurred during the first $200 \mathrm{msec}$ after onset of the startle-eliciting whitenoise burst. Footshock reactions were measured in the same way that noise-evoked startle responses were measured with the exception that the accelerometers' output was sampled for 500 rather than $200 \mathrm{msec}$.

The CS was a 3.7-sec light (82 lux) produced by an 8-watt fluorescent bulb (100-usec rise time) located $10 \mathrm{~cm}$ behind each cage. Luminosity was measured using a VWR light meter (Atlanta, GA). The unconditioned stimulus was a $0.5-\mathrm{sec} 0.4-\mathrm{mA}$ scrambled footshock delivered across the floorbars of the test cage. Shocks were produced by BRS/LVE shock generators (SGS004). Shock intensity was measured with a $1-\mathrm{k} \Omega$ resistor across a differential channel of an oscilloscope in series with a $100-\mathrm{k} \Omega$ resistor connected between different floor bars within each cage. Current was defined as the root mean square voltage across the 1 - $\mathrm{k} \Omega$ resistor where $\mathrm{mA}=0.707 \times 0.5 \times$ peak-to-peak voltage.

The presentation and sequencing of all stimuli were under the control of the Macintosh G3 computer using customdesigned software (The Experimenter; Glassbeads Inc.).

\section{Surgery}

Rats were anesthetized with sodium pentobarbital $(50 \mathrm{mg} / \mathrm{kg}$ i.p.), injected with atropine sulphate $(10 \mathrm{mg} / \mathrm{kg}$ i.p) to reduce congestion and with an analgesic dose of buprenorphine (0.04 $\mathrm{mg} / \mathrm{kg}$, s.c.) to reduce postoperative discomfort. Once unresponsive to tailpinch, rats were placed in a Kopf Instruments stereotaxic frame with the nosebar set to $-3.6 \mathrm{~mm}$ (flat-skull position). The skull was exposed and 22-gauge guide cannulae (Plastic Products, Model C313G) were implanted bilaterally with the tips aimed $3.3 \mathrm{~mm}$ caudal, $8.2 \mathrm{~mm}$ ventral, and $5.4 \mathrm{~mm}$ lateral to bregma. Four jeweler screws were attached to the skull, and the entire assembly was cemented in place using Cranioplastic Powder (Plastic Products). Stainless steel wires (i.e., stylets) were inserted into the guide cannula to maintain patency. The tip of each extended $\sim 1 \mathrm{~mm}$ past the end of the guide cannula. A second dose of buprenorphine was administered $\sim 12 \mathrm{~h}$ after surgery. A minimum of $8 \mathrm{~d}$ elapsed between cannula implantation and the onset of behavioral procedures.

\section{Behavioral procedures}

Behavioral procedures began with an acclimation session in which rats were placed into the startle chamber and after 5 min, presented with 30 95-dB startle-eliciting white-noise bursts (onset-to-onset interstimulus interval [ISI] $=30 \mathrm{sec}$ ).

On the following day, rats were returned to the startle chamber whereupon they received 10 light-shock pairings. The first occurred $5 \mathrm{~min}$ after the rats were placed into the startle apparatus, and successive pairings occurred every $2 \mathrm{~min}$. Thus, the procedure was completed within $25 \mathrm{~min}$ of the rats being placed into the startle chamber. For each pairing, the 0.5-sec shock was delivered $3.2 \mathrm{sec}$ after onset of the 3.7-sec visual CS. As specified 
later, rats in different experiments received either 1 or 2 fear conditioning sessions.

Twenty-four hours later, rats that were to receive pretest infusions received a brief drug-free pretest. The data from this test were used to assign rats to different treatment groups such that the mean level of fear-potentiated startle, prior to drug treatment, was comparable in each. For this test, rats were placed into the test chamber where, after $5 \mathrm{~min}$, they received 20 startleeliciting noise bursts (ISI $=30 \mathrm{sec}$ ). Five of the final 10 noise bursts were presented $3.2 \mathrm{sec}$ after onset of the visual CS (lightnoise trial type) and the other 5 were presented, on alternating trials, in the absence of the CS (i.e., noise alone trial type). Using these final 10 startle responses, a fear-potentiated startle score was calculated for each rat as described in the "Statistical Analyses" section.

Approximately $48 \mathrm{~h}$ after the final conditioning session (and $24 \mathrm{~h}$ after the drug-free pretest for those animals that received it), all rats were tested using a procedure similar to that just described. For this test, however, rats received 75 noise bursts-with 30 of the final 60 being presented $3.2 \mathrm{sec}$ after onset of the visual CS (light-noise trial type) and the other 30 being presented in the absence of the CS (noise alone trial type). For each block of 2 consecutive trials, one noise alone and one light-noise trial was presented, with the order of the two trial types varying randomly for each block.

\section{Drugs and infusion procedure}

Rats were infused with either CP101,606 $(0.5,1.5$, or $4.5 \mu \mathrm{g} /$ amygdala) or NVP-AAM077 $(0.075,0.25,0.75$, or $2.5 \mu \mathrm{g} /$ amygdala) dissolved in phosphate-buffered saline (PBS), or with PBS alone. For rats that received pretraining infusions, drugs were infused prior to each of either 1 or 2 conditioning sessions. Infusions $(0.25 \mu \mathrm{l} / \mathrm{min}, 0.5-\mu \mathrm{l}$ total volume/amygdala) were made through 28-gauge injection cannulae (Plastic Products, Model C313I) that were attached by polyethylene tubing to a microsyringe. Injection cannulae were left in place for $2 \mathrm{~min}$ after the infusion was completed, after which the stylets were placed back into the guide cannula and the rats were placed into the test cages.

CP101,606 was generously supplied by Dr. Frank Menniti of Pfizer Inc.. The doses were chosen based on estimates of the relative efficacy of CP101,606 versus the NR1/NR2B antagonist ifenprodil for disrupting NR2B-containing receptor-mediated EPSCs in amygdala neurons (Lopez de Armentia and Sah 2003; Sah and Lopez De Armentia 2003) together with previous dose-response analyses of intra-amygdala ifenprodil effects on fear conditioning as assessed with freezing (Rodrigues et al. 2001), and on our own pilot data with this compound. NVP-AAM077 was generously supplied by Dr. Yves P. Auberson of the Novartis Institutes for BioMedical Sciences. These doses were selected based, in part, on the relative concentrations of NVP-AAM077 and CP101,606 that have been used to block NR2A- versus NR2B-mediated currents, respectively, in previously published electrophysiological experiments (Liu et al. 2004), and on our own preliminary behavioral data.

\section{Statistical analyses}

For each rat, the mean startle amplitude on noise alone and on light-noise trials was determined and a percent change score calculated ([mean startle amplitude on light-noise test trials minus mean startle amplitude on noise alone test trials]/[mean startle amplitude on noise alone test trials] $\times 100$; Walker and Davis $2002 \mathrm{a}$ ). For animals that received two conditioning sessions, fearpotentiated startle scores were calculated from the final 60 test trials (i.e., the 30 light-noise and 30 noise alone trials of the full test session). However, with only a single conditioning session, within-session extinction during the full test was often apparent during the later trials. Therefore, for all animals trained with a single session, fear-potentiated startle scores were calculated using startle responses obtained from the first 10 light-noise trials and from the corresponding (i.e., intermixed) noise alone test trials-a period during which fear-potentiated startle scores showed no systematic change.

The scores for all animals were analyzed using ANOVA with Dose and Training (i.e., 1 versus 2 conditioning sessions) as between-group factors. Separate ANOVAs were performed for the effect of CP101,606 and for NVP-AAM077 using data from the same PBS-infused animals as a common control. Post-hoc comparisons were made using Dunnett's $t$-tests (two-tailed) for multiple comparisons with a control. Also, single-sample $t$-tests were used to determine if the fear-potentiated startle scores for any individual group were significantly different from $0 \%$ potentiation. Similar analyses were performed on baseline startle amplitude (i.e., from the noise alone test trials), and also on the rats' footshock reactions. Inferential statistics were performed using SPSS software (version 13.0.0; SPS, Inc., Chicago, IL).

\section{Histology}

Rats were sacrificed by chloral hydrate overdose and perfused intracardially with $0.9 \%(\mathrm{wt} / \mathrm{vol})$ saline followed by $10 \%$ (vol/ vol) formalin. The brains were removed and immersed in a $30 \%$ (wt/vol) sucrose-formalin solution for at least $3 \mathrm{~d}$, after which $40-\mu \mathrm{m}$ coronal sections were cut through the area of interest. Every fourth section was mounted and stained with cresyl violet. Cannulae placements and the determination as to whether the cannula was within or sufficiently near the intended target to be scored as a hit (within $0.5 \mathrm{~mm}$ of the central amygdala nucleus or basolateral amygdala complex but not in a ventricle and not lateral to an intact external capsule) were judged by a scorer blind to the animal's group assignment and behavioral data.

\section{Acknowledgments}

This research was supported by National Institute of Mental Health grants MH47840, MH57250 and MH59906, and the Science and Technology Center (The Center for Behavioral Neuroscience of the National Science Foundation under Agreement no. IBN-9876754) and the Yerkes Base Grant. CP101,606 was a generous gift from Dr. Frank Menniti of Pfizer, Inc. NVP-AAM077 was generously supplied by Dr. Yves P. Auberson of the Novartis Institutes for BioMedical Sciences (Basel, Switzerland).

\section{References}

Barria, A. and Malinow, R. 2005. NMDA receptor subunit composition controls synaptic plasticity by regulating binding to CaMKII. Neuron 48: 289-301.

Bartanusz, V., Aubry, J.M., Pagliusi, S., Jezova, D., Baffi, J., and Kiss, J.Z. 1995. Stress-induced changes in messenger RNA levels of $\mathrm{N}$-methyl-D-aspartate and AMPA receptor subunits in selected regions of the rat hippocampus and hypothalamus. Neuroscience 66: $247-252$.

Bartlett, T.E., Bannister, N.J., Collett, V.J., Dargan, S.L., Massey, P.V., Bortolotto, Z.A., Fitzjohn, S.M., Bashir, Z.I., Collingridge, G.L., and Lodge, D. 2007. Differential roles of NR2A and NR2B-containing NMDA receptors in LTP and LTD in the CA1 region of two-week old rat hippocampus. Neuropharmacology 52: 60-70.

Bauer, E.P., Schafe, G.E., and LeDoux, J.E. 2002. NMDA receptors and L-type voltage-gated calcium channels contribute to long-term potentiation and different components of fear memory formation in the lateral amygdala. J. Neurosci. 22: 5239-5249.

Bayer, K.U., De Koninck, P., Leonard, A.S., Hell, J.W., and Schulman, H. 2001. Interaction with the NMDA receptor locks CaMKII in an active conformation. Nature 411: 801-805.

Beaton, J.A., Stemsrud, K., and Monaghan, D.T. 1992. Identification of a novel N-methyl-D-aspartate receptor population in the rat medial thalamus. J. Neurochem. 59: 754-757.

Blair, H.T., Sotres-Bayon, F., Moita, M.A.P., and LeDoux, J.E. 2005. The lateral amygdala processes the value of conditioned and unconditioned aversive stimuli. Neuroscience 133: 561-569.

Buller, A.L., Larson, H.C., Schneider, B.E., Beaton, J.A., Morrisett, R.A., and Monaghan, D.T. 1994. The molecular basis of NMDA receptor subtypes: Native receptor diversity is predicted by subunit composition. J. Neurosci. 14: 5471-5484.

Campeau, S., Miserendino, M.J.D., and Davis, M. 1992. Intra-amygdala infusion of the N-methyl-D-aspartate receptor antagonist AP5 blocks acquisition but not expression of fear-potentiated startle to an auditory conditioned stimulus. Behav. Neurosci. 106: 569-574. 
Chapman, P.F. and Bellavance, L.L. 1992. Induction of long-term potentiation in the basolateral amygdala does not depend on NMDA receptor activation. Synapse 11: 310-318.

Chazot, P.L., Lawrence, S., and Thompson, C.L. 2002. Studies on the subtype selectivity of CP-101,606: Evidence for two classes of NR2B-selective NMDA receptor antagonists. Neuropharmacology 42: 319-324.

Chenard, B.L., Shalaby, I.A., Koe, B.K., Rounau, R.T., Butler, T.W., Prochniak, M.A., Schmidt, A.W., and Fox, C.B. 1991. Separation of $\mathrm{a}_{1}$ adrenergic and $\mathrm{N}$-methyl-D-aspartate antagonist activity in a series of ifenprodil compounds. J. Med. Chem. 34: 3085-3090.

Chenard, B.L., Bordner, J., Butler, T.W., Chambers, L.K., Collins, M.A., De Costa, D.L., Ducat, M.F., Dumont, M.L., Fox, C.B., and Mena, E.E. 1995. (1S,2S)-1-(4-hydroxyphenyl)-2-(4-hydroxy-4-phenylpiperidino)-1-propanol: A potent new neuroprotectant which blocks N-methyl-D-aspartate responses. J. Med. Chem. 38: 3138-3145.

Cull-Candy, S., Brickley, S., and Farrant, M. 2001. NMDA receptor subunits: Diversity, development and disease. Curr. Opin. Neurobiol. 11: $327-335$

Danober, L., Heinbockel, T., Driesang, R.B., and Pape, H.C. 2000. Synaptic mechanisms of NMDA-mediated hyperpolarization in lateral amygdaloid projection neurons. Neuroreport 11: 2501-2506.

Ehlers, M.D. 2003. Activity level controls postsynaptic composition and signaling via the ubiquitin-proteasome system. Nat. Neurosci. 6: 231-242.

Farb, C.R., Aoki, C., and LeDoux, J.E. 1995. Differential localization of NMDA and AMPA receptor subunits in the lateral and basal nuclei of the amygdala: A light and electron microscopic study. J. Comp. Neurol. 362: 1-23.

Fendt, M. 2001. Injections of the NMDA receptor antagonist aminophosphonopentanoic acid into the lateral nucleus of the amygdala block the expression of fear-potentiated startle and freezing. J. Neurosci. 21: 4111-4115.

Feng, B., Tse, H.W., Skifter, D.A., Morley, R., Jane, D.E., and Monaghan, D.T. 2004. Structure-activity analysis of a novel NR2C/NR2Dpreferring NMDA receptor antagonist: 1-(phenanthrene-2-carbonyl) piperazine-2,3-dicarboxylic acid. Br. J. Pharmacol. 141: 508-516.

Fox, C.J., Russell, K.I., Wang, Y.T., and Christie, B.R. 2006. Contribution of NR2A and NR2B NMDA subunits to bidirectional synaptic plasticity in the hippocampus in vivo. Hippocampus 16: 907-915.

Fujisawa, S. and Aoki, C. 2003. In vivo blockade of $\mathrm{N}$-methyl-D-aspartate receptors induces rapid trafficking of NR2B subunits away from synapses and out of spines and terminals in adult cortex. Neuroscience 121: 51-63.

Humeau, Y., Shaban, H., Bissiere, S., and Luthi, A. 2003. Presynaptic induction of heterosynaptic associative plasticity in the mammalian brain. Nature 426: 841-845.

Jasnow, A.M., Cooper, M.A., and Huhman, K.L. 2004. $\mathrm{N}$-methyl-D-aspartate receptors in the amygdala are necessary for the acquisition and expression of conditioned defeat. Neuroscience 123: 625-634.

Karbon, E.W., Patch, R.J., Pontecorvo, M.J., and Ferkany, J.W. 1990. Ifenprodil potently interacts with $\left[{ }^{3} \mathrm{H}\right](+)-3$-PPP-labeled $\sigma$ binding sites in guinea pig brain membranes. Eur. J. Pharmacol. 176: $247-248$.

Kew, J.N., Trube, G., and Kemp, J.A. 1996. A novel mechanism of activity-dependent NMDA receptor antagonism describes the effect of ifenprodil in rat cultured cortical neurones. J. Physiol. 497: 761-772.

Kojima, N., Sakamoto, T., Endo, S., and Niki, H. 2005. Impairment of conditioned freezing to tone, but not to context, in Fyn-transgenic mice: Relationship to NMDA receptor subunit 2B function. Eur. J. Neurosci. 21: 1359-1369.

LaLumiere, R.T., Pizano, E., and McGaugh, J.L. 2004. Intra-basolateral amygdala infusions of AP-5 impair or enhance retention of inhibitory avoidance depending on training conditions. Neurobiol. Learn. Mem. 81: 60-66.

Laurie, D.J., Bartke, I., Schoepfer, R., Naujoks, K., and Seeburg, P.H. 1997. Regional, developmental and interspecies expression of the four NMDAR2 subunits, examined using monoclonal antibodies. Brain Res. Mol. Brain Res. 51: 23-32.

Lee, E.H.Y., Lin, Y.P., and Yin, T.H. 1988. Effects of lateral and medial septal lesions on various activity and reactivity measures in the rat. Physiol. Behav. 42: 97-102.

Lee, H.J., Choi, J.S., Brown, T.H., and Kim, J.J. 2001. Amygdalar NMDA receptors are critical for the expression of multiple conditioned fear responses. J. Neurosci. 21: 4116-4124.

Li, X.F., Stutzmann, G.E., and LeDoux, J.E. 1996. Convergent but temporally separated inputs to lateral amygdala neurons from the auditory thalamus and auditory cortex use different postsynaptic receptors: In vivo intracellular and extracellular recordings in fear conditioning pathways. Learn. Mem. 3: 229-242.
Lindquist, D.H. and Brown, T.H. 2004. Amygdalar NMDA receptors control the expression of associative reflex facilitation and three other conditional responses. Behav. Neurosci. 118: 36-52.

Liu, L., Wong, T.P., Pozza, M.F., Lingenhoehl, K., Wang, Y., Sheng, M., Auberson, Y.P., and Wang, Y.T. 2004. Role of NMDA receptor subtypes in governing the direction of hippocampal synaptic plasticity [see comment]. Science 304: 1021-1024.

Loftis, J.M. and Janowsky, A. 2003. The N-methyl-D-aspartate receptor subunit NR2B: Localization, functional properties, regulation, and clinical implications. Pharmacol. Ther. 97: 55-85.

Lopez de Armentia, M. and Sah, P. 2003. Development and subunit composition of synaptic NMDA receptors in the amygdala: NR2B synapses in the adult central amygdala. J. Neurosci. 23: 6876-6883.

Lu, L., Dempsey, J., Shaham, Y., and Hope, B.T. 2005. Differential long-term neuroadaptations of glutamate receptors in the basolateral and central amygdala after withdrawal from cocaine self-administration in rats. J. Neurochem. 94: 161-168.

Mahanty, N.K. and Sah, P. 1999. Excitatory synaptic inputs to pyramidal neurons of the lateral amygdala. Eur. J. Neurosci. 11: $1217-1222$.

Maren, S. and Fanselow, M.S. 1995. Synaptic plasticity in the basolateral amygdala induced by hippocampal formation stimulation in vivo. $J$ Neurosci. 15: 7548-7564.

Maren, S., Aharonov, G., Stote, D., and Fanselow, M. 1996. $\mathrm{N}$-methyl-D-aspartate receptors in the basolateral amygdala are required for both acquisition and expression of conditional fear in rats. Behav. Neurosci. 110: 1365-1374.

Massey, P.V., Johnson, B.E., Moult, P.R., Auberson, Y.P., Brown, M.W. Molnar, E., Collingridge, G.L., and Bashir, Z.I. 2004. Differential roles of NR2A and NR2B-containing NMDA receptors in cortical long-term potentiation and long-term depression. J. Neurosci. 24: 7821-7828.

Matus-Amat, P., Higgins, E.A., Sprunger, D., Wright-Hardesty, K., and Rudy, J.W. 2007. The role of dorsal hippocampus and basolateral amygdala NMDA receptors in the acquisition and retrieval of context and contextual fear memories. Behav. Neurosci. 121: $721-731$.

McCool, B.A. and Lovinger, D.M. 1995. Ifenprodil inhibition of the 5-hydroxytryptamine3 receptor. Neuropharmacology 34: 621-629.

Miserendino, M.J.D., Sananes, C.B., Melia, K.R., and Davis, M. 1990. Blocking of acquisition but not expression of conditioned fear-potentiated startle by NMDA antagonists in the amygdala. Nature 345: 716-718.

Monyer, H., Sprengel, R., Schoepfer, R., Herb, A., Higuchi, M., Lomeli, H., Burnashev, N., Sakmann, B., and Seeburg, P.H. 1992. Heteromeric NMDA receptors: Molecular and functional distinction of subtypes. Science 256: 1217-1221.

Monyer, H., Burnashev, N., Laurie, D.J., Sakmann, B., and Seeburg, P.H. 1994. Developmental and regional expression in the rat brain and functional properties of four NMDA receptors. Neuron 12: 529-540.

Mott, D.D., Doherty, J.J., Zhang, S., Washburn, M.S., Fendley, M.J., Lyuboslavsky, P., Traynelis, S.F., and Dingledine, R. 1998. Phenylethanolamines inhibit NMDA receptors by enhancing proton inhibition. Nat. Neurosci. 1: 659-667.

Nagy, J., Horvath, C., Farkas, S., Kolok, S., and Szombathelyi, Z. 2004. NR2B subunit selective NMDA antagonists inhibit neurotoxic effect of alcohol-withdrawal in primary cultures of rat cortical neurones. Neurochem. Int. 44: 17-23.

Nakazawa, T., Komai, S., Watabe, A.M., Kiyama, Y., Fukaya, M. Arima-Yoshida, F., Horai, R., Sudo, K., Ebine, K., Delawary, M., et al. 2006. NR2B tyrosine phosphorylation modulates fear learning as well as amygdaloid synaptic plasticity. EMBO J. 25: 2867-2877.

Neyton, J. and Paoletti, P. 2006. Relating NMDA receptor function to receptor subunit composition: limitations of the pharmacological approach. J. Neurosci. 26: 1331-1333.

Priestley, T., Laughton, P., Myers, J., Le Bourdelles, B., Kerby, J., and Whiting, P.J. 1995. Pharmacological properties of recombinant human N-methyl-D-aspartate receptors comprising NR1a/NR2A and NR1a/NR2B subunit assemblies expressed in permanently transfected mouse fibroblast cells. Mol. Pharmacol. 48: 841-848.

Prybylowski, K. and Wenthold, R.J. 2004. N-Methyl-D-aspartate receptors: Subunit assembly and trafficking to the synapse. J. Biol. Chem. 279: 9673-9676.

Rodrigues, S.M., Schafe, G.E., and LeDoux, J.E. 2001. Intra-amygdala blockade of the NR2B subunit of the NMDA receptor disrupts the acquisition but not the expression of fear conditioning. J. Neurosci. 21: 6889-6896.

Sah, P. and Lopez De Armentia, M. 2003. Excitatory synaptic transmission in the lateral and central amygdala. Ann. N. Y. Acad. Sci. 985: 67-77.

Samson, R.D. and Pare, D. 2005. Activity-dependent synaptic plasticity in the central nucleus of the amygdala. J. Neurosci. 25: 1847-1855. 
Shin, R.M., Tsvetkov, E., and Bolshakov, V.Y. 2006. Spatiotemporal asymmetry of associative synaptic plasticity in fear conditioning pathways. Neuron 52: 883-896.

Sotres-Bayon, F., Bush, D.E., and LeDoux, J.E. 2007. Acquisition of fear extinction requires activation of NR2B-containing NMDA receptors in the lateral amygdala. Neuropsychopharmacology 32: 1929-1940.

Szinyei, C., Stork, O., and Pape, H.C. 2003. Contribution of NR2B subunits to synaptic transmission in amygdaloid interneurons. $J$. Neurosci. 23: 2549-2556.

Tang, Y.P., Shimizu, E., Dube, G.R., Rampon, C., Kerchner, G.A., Zhuo, M., Liu, G., and Tsien, J.Z. 1999. Genetic enhancement of learning and memory in mice. Nature 401: 25-27.

Thomas, K.L., Davis, S., Hunt, S.P., and Laroche, S. 1996. Alterations in the expression of specific glutamate receptor subunits following hippocampal LTP in vivo. Learn. Mem. 3: 197-208.

Tovar, K.R., Sprouffske, K., and Westbrook, G.L. 2000. Fast NMDA receptor-mediated synaptic currents in neurons from mice lacking the $\varepsilon 2$ (NR2B) subunit. J. Neurophysiol. 83: 616-620.

Tsien, J.Z. 2000. Linking Hebb's coincidence-detection to memory formation. Curr. Opin. Neurobiol. 10: 266-273.

Vicini, S., Wang, J.F., Li, J.H., Zhu, W.J., Wang, Y.H., Luo, J.H., Wolfe, B.B., and Grayson, D.R. 1998. Functional and pharmacological differences between recombinant $N$-methyl-D-aspartate receptors. $J$. Neurophysiol. 79: 555-566.

Walker, D.L. and Davis, M. 2000. Involvement of $N$-methyl-D-aspartate (NMDA) receptors within the amygdala in short- versus long-term memory for fear conditioning as assessed with fear-potentiated startle. Behav. Neurosci. 114: 1019-1033.

Walker, D.L. and Davis, M. 2002a. Quantifying fear potentiated startle using absolute versus percent increase scoring methods: Implications for the neurocircuitry of fear and anxiety. Psychopharmacology 164: $318-328$.

Walker, D.L. and Davis, M. 2002b. The role of glutamate receptors within the amygdala in fear learning, fear-potentiated startle, and extinction. Pharmacol. Biochem. Behav. 71: 379-392.

Walker, D.L., Paschall, G.Y., and Davis, M. 2005. Glutamate receptor antagonist infusions into the basolateral and medial amygdala reveal differential contributions to olfactory vs. context fear conditioning and expression. Learn. Mem. 12: 120-129.

Weisskopf, M.G. and LeDoux, J.E. 1999. Distinct populations of NMDA receptors at subcortical and cortical inputs to principal cells of the lateral amygdala. J. Neurophysiol. 81: 930-934.

Weitlauf, C., Honse, Y., Auberson, Y.P., Mishina, M., Lovinger, D.M. and Winder, D.G. 2005. Activation of NR2A-containing NMDA receptors is not obligatory for NMDA receptor-dependent long-term potentiation. J. Neurosci. 25: 8386-8390.

Williams, K. 1993. Ifenprodil discriminates subtypes of the N-methyl-D-aspartate receptor: Selectivity and mechanisms at recombinant heteromeric receptors. Mol. Pharmacol. 44: 851-859.

Williams, J.M., Mason-Parker, S.E., Abraham, W.C., and Tate, W.P. 1998 Biphasic changes in the levels of $N$-methyl-D-aspartate receptor- 2 subunits correlate with the induction and persistence of long-term potentiation. Brain Res. Mol. Brain Res. 60: 21-27.

Woodhall, G., Evans, D.I., Cunningham, M.O., and Jones, R.S. 2001. NR2B-containing NMDA autoreceptors at synapses on entorhinal cortical neurons. J. Neurophysiol. 86: 1644-1651.

Wu, L.J., Toyoda, H., Zhao, M.G., Lee, Y.S., Tang, J., Ko, S.W., Jia, Y.H., Shum, F.W., Zerbinatti, C.V., Bu, G., et al. 2005. Upregulation of forebrain NMDA NR2B receptors contributes to behavioral sensitization after inflammation. J. Neurosci. 25: 11107-11116.

Zhang, X.X., Bunney, B.S., and Shi, W.X. 2000. Enhancement of NMDA-induced current by the putative NR2B selective antagonist ifenprodil. Synapse 37: 56-63.

Received October 9, 2007; accepted in revised form December 2, 2007. 


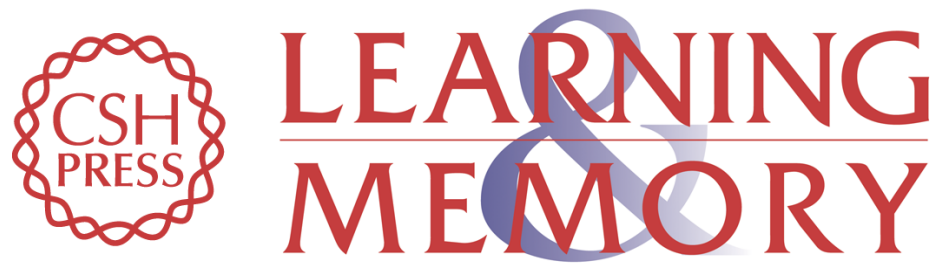

\section{Amygdala infusions of an NR2B-selective or an NR2A-preferring NMDA receptor antagonist differentially influence fear conditioning and expression in the fear-potentiated startle test}

David L. Walker and Michael Davis

Learn. Mem. 2008, 15:

Access the most recent version at doi:10.1101//m.798908

References This article cites 73 articles, 21 of which can be accessed free at:

http://learnmem.cshlp.org/content/15/2/67.full.html\#ref-list-1

License

Email Alerting

Receive free email alerts when new articles cite this article - sign up in the box at the Service top right corner of the article or click here. 